\title{
Paediatric and young adult population with type 2 diabetes as a challenge for family medicine: an 8 year national observational study
}

\author{
MARIUSZ JAWORSKI 1, A, E, F, MARIUSZ PANCZYK ${ }^{1, c, ~ D, ~ A N D R Z E J ~ S ́ L I W C Z Y N ́ S K I 2, ~ B, ~}$ \\ ORCID ID: 0000-0002-5207-8323 ORCID ID: 0000-0003-1830-2114 \\ MELANIA BRZOZOWSKA ${ }^{2, \text { B }, ~ J O A N N A ~ G O T L I B ~}{ }^{1, A, G}$ \\ ORCID ID: 0000-0002-2717-7741
}

\author{
${ }^{1}$ Department of Education and Research in Health Sciences, Faculty of Health Sciences, Medical University \\ of Warsaw, Warsaw, Poland \\ ${ }^{2}$ Department of Analysis and Strategy, The National Health Fund, Warsaw, Poland
}

A - Study Design, B - Data Collection, C - Statistical Analysis, D - Data Interpretation, E - Manuscript Preparation, F - Literature Search, G - Funds Collection

Summary Background. Literature points out that the frequency of occurrence of type 2 diabetes mellitus (T2DM) in children, adolescents and young adults has been increasing rapidly. However, there is still lack of epidemiological research in this area.

Objectives. The national observation study was used to determine the trend of T2DM in the Polish paediatric and young adult population.

Material and methods. The Polish National Health Fund database from 2010 to 2017, which was representative of the Polish population, was examined. Overall, 8,530 patients with T2DM were included in the study. The annual prevalence of T2DM was estimated according to the age groups, especially in three groups: group 1 - children (up to 10 years of age), group 2 - adolescents (between 11 and 20 years of age) and group 3-young adults (21-30 years of age). The T2DM groups were defined according to the ICD-10 codes. The relative risk (RR) with a $95 \%$ confidence interval $(95 \% \mathrm{Cl})$ was also calculated.

Results. The frequency of occurrence of T2DM in the population of children and adolescents is relatively stable and reached - depending on the year of observation - between $0.33 \%$ and $0.22 \%$ of all T2DM patients. Each year, physicians diagnose about 255 new cases of T2DM among children up to 10 years of age and about 812 among adolescents between 11 and 20 years of age.

Conclusions. The tendency of occurrence of T2DM among children and teenagers is relatively stable. This problem requires taking appropriate steps in order to prevent the development of T2DM and improve medical care aimed at these patients.

Key words: type 2 diabetes mellitus, observational study, adolescent medicine, young adult, children.

Jaworski M, Panczyk M, Śliwczyński A, Brzozowska M, Gotlib J. Paediatric and young adult population with type 2 diabetes as a challenge for family medicine: an 8 year national observational study. Fam Med Prim Care Rev 2021; 23(1): 17-21, doi: https://doi.org/10.5114/ fmpcr.2021.103152.

\section{Background}

The number of patients affected by type 2 diabetes mellitus (T2DM) is increasing globally [1], and it will be a challenge for family medicine and primary care. According to research, there are more than 500 million prevalent cases of T2DM globally [2], and the prevalence is very similar in high- and low-income countries. However, differences are observed in different geographical regions. The prevalence of T2DM in the paediatric population is higher in the United States than in Europe $(12 / 100000$ and 2.5/100 000, respectively). Additionally, screening studies have shown that T2DM occurs in up to $1 \%$ of obese children $\geq 12$ years of age [3]. Other epidemiologic studies have shown that the incidence of T2DM in the paediatric population depends upon the ethnic group. Generally, this is within a range of $1-51 / 1000$. Epidemiological data suggests that the average age of onset of T2DM in the paediatric population is 13 years of age [4]

Appropriate knowledge of T2DM epidemiology in the paediatric and young adult population and the skill of medical staff (e.g. nurses, doctors, dietitians) to work with these children and adolescents is an important challenge for contemporary family medicine. Many nurses and doctors take part in health education, including nutrition education, for adult patients with T2DM. However, education concerning children and adolescents in this area has a different specificity. The increasing number of children and adolescents with T2DM suggests the need to strengthen the appropriate skills of medical staff. Literature stresses the fact that the spread of T2DM may occur in people of different ages [5]. Previously, this type of diabetes was associated exclusively with adults and was even named 'adult-onset diabetes'. Nowadays, it is recognised that T2DM may also affect children, teenagers and young adults $[3,6]$. Due to this fact, the name used more frequently is 'noninsulin-dependent diabetes' instead of 'adult-onset diabetes'.

Literature lacks works that would describe this phenomenon in a greater detail. For instance, evidence suggests that T2DM in the paediatric population is completely different from T2DM in adults. For this reason, health education concerning children and adolescents requires a different approach. Nurses, doctors and their skills could play an important role in this context [6]. Thus, it is well-grounded to undertake research not only aimed at determining the scale of the discussed phenomenon but also to specify its trends in different age groups. 


\section{Objectives}

The objective of this study was to evaluate the frequency of occurrence of T2DM in Polish children, adolescents and young adults between the years 2010-2017. Particular attention was paid to determining the frequency of occurrence of T2DM in three groups: children (up to 10 years of age), adolescents (between 11 and 20 years of age) and young adults (21-30 years of age).

\section{Material and methods}

\section{Type of study}

A population-based observational study [7] was used. This observational study include all patients within a given jurisdiction and who were therefore less prone to the selection and referral biases that plague more traditional forms of observational research. Moreover, a population-based observational study has a good external validity and provides insight into the delivery of care in routine practice to all patients, including the elderly. In the present study, retrospective data collected for T2DM patients from January 2010 to December 2017 was analysed.

\section{Source of database}

The National Health Information (NHI) database maintained by the Polish National Health Fund (NFZ) was used. This database of medical data was created based on Polish legal regulations. Collecting medical data is regulated by the Regulation of the Minister of Health of 20 June 2008 (last amendment on 1 July 2017). According to this regulation, all patients whose treatment was financed from public funds are registered. This database has registered patients from state medical centres and private medical centres that signed a contract with the NFZ, under which medical services are financed from public funds [8]. This database includes specific information on the demographic characteristics (genndder and age), consultation statements and diagnosis by the ICD-10 [9]. Visit sampling and data collection were recorded on patient record forms by hospital staff or by field representatives from the NFZ. The data collection methods do not indicate that data recording by hospital staff was done prospectively. Therefore, this study should be considered (conservatively) as a retrospective chart review. Data processing and coding were performed by the NFZ.

\section{Patients}

Inclusion criteria included: 1) T2DM diagnosed by a diabetologist in line with ICD-10 [9], 2) the study included patients up to 30 years of age, 3) patients with T2DM who more than once in a given year from January 2010 to December 2017 were included. They all made at least one visit to outpatient care or inpatient care for a diagnosis of T2DM. Only patients fulfilling the above-mentioned criteria were included.
The selection of patients for the study consisted of two stages. The first stage was related to the selection of all T2DM patients from the NHF database, regardless of their age. In the second stage, we selected only children and adolescents with T2DM. Overall, 8,530 patients with T2DM were included in the study and were divided into three groups: children (up to 10 years of age), adolescents (between 11 and 20 years of age) and young adults (21-30 years of age).

In Poland, diabetes treatment is mainly financed from public funds. Most Polish patients undertake treatment make use of the national budget. For this reason, a prevailing number of patients with T2DM benefit from state medical care [10].

\section{Ethical consideration}

Our study is a retrospective data analysis from the period of 2010-2017, and our data comes from a public database. For this reason, we did not require approval from an independent ethics committee (IEC). The authors sought advice from the Bioethics Committee of the Medical University of Warsaw to conduct the presented study. As the "commission does not issue opinions on the survey, retrospective and other non-invasive scientific studies", approval was not required. The owners of the data gave their permission to use this information.

\section{Statistical analysis}

The demographic characteristics for T2DM patients were analysed through descriptive statistics. The annual prevalence of T2DM was estimated according to the age groups, especially in three groups: group 1 - children (up to 10 years of age), group 2 - adolescents (between 11 and 20 years of age) and group 3 - young adults (21-30 years of age). In order to represent the percentage of children and young adults contrasted with the total group, we divided all patients with T2DM into two subgroups: the first subgroup is children and adolescents up to 20 years of age, while the second one is for those over 20 years of age. It should be noted that all T2DM patients were included in this group, not only young adults (21-30 years of age).

For the incidence of T2DM in the paediatric population, with reference to all patients with T2DM in the years 2010-2017 , the relative risk (RR) with a $95 \%$ confidence interval (95\% CI) was calculated [11]. For this purpose, patient data pertaining the general patient number benefiting from state medical care in Poland, the number of patients diagnosed with T2DM and the number of children and adolescents with T2DM were all calculated separately.

\section{Results}

Figure 1 presents the frequency of occurrence of T2DM in the paediatric population in three subgroups. The trend of occurrence of T2DM in the first two age groups was relatively stable and concerned on average 255 children up to 10 years

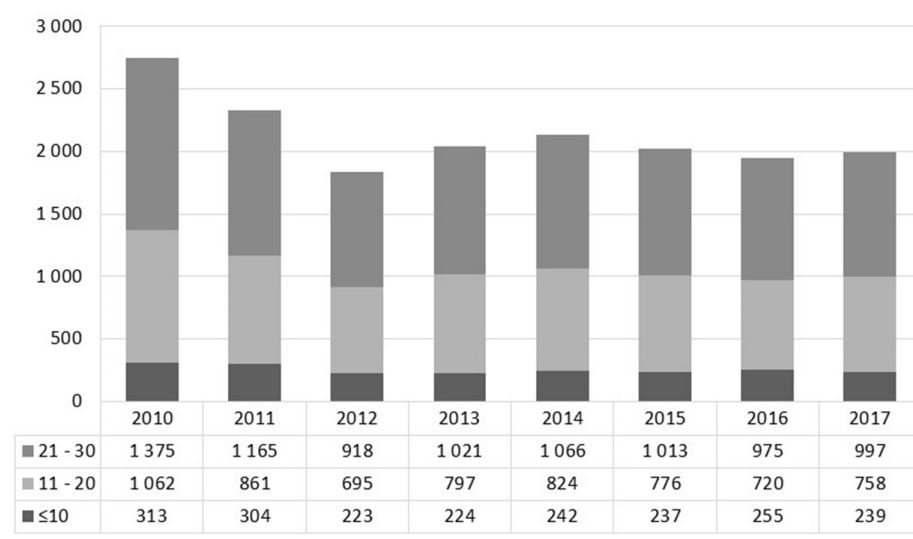

Figure 1. Trend of T2DM in pediatric population between 2010-2017

Legend: The vertical axis shows the number of T2DM patients, the horizontal axis shows the year of follow-up. Different colours illustrate the number of patients in the three groups. 
of age and 812 adolescents between 11 and 20 years of age. A significant increase in the frequency of diagnosed diabetes was observed in patients over 20 . While analysing these three age groups, it can be observed that the frequency of diagnosis of type 2 diabetes was the highest in the group of young adults (21-30 years of age).

Table 1 presents the overall percentage of children and adolescents up to 20 years of age (group 1 and 2 together) contrasted with the total number of patients with T2DM. Depending on the year of observation, children and youth comprised between $0.33 \%$ and $0.22 \%$ of all patients with T2DM.

\begin{tabular}{|c|c|c|c|c|}
\hline \multirow[t]{2}{*}{ Year } & \multirow[t]{2}{*}{ Total T2DM } & \multicolumn{2}{|c|}{ Age group } & \multirow{2}{*}{$\begin{array}{l}\% \text { of children } \\
\text { and adolescents } \\
\text { with T2DM in } \\
\text { the group }\end{array}$} \\
\hline & & $>20$ & $\leq 20$ & \\
\hline 2010 & 420847 & 419472 & 1375 & $0.33 \%$ \\
\hline 2011 & 355349 & 354184 & 1165 & $0.33 \%$ \\
\hline 2012 & 357202 & 356284 & 918 & $0.26 \%$ \\
\hline 2013 & 440030 & 439009 & 1021 & $0.23 \%$ \\
\hline 2014 & 454353 & 453287 & 1066 & $0.23 \%$ \\
\hline 2015 & 446465 & 445452 & 1013 & $0.23 \%$ \\
\hline 2016 & 444025 & 443050 & 975 & $0.22 \%$ \\
\hline 2017 & 436643 & 435646 & 997 & $0.23 \%$ \\
\hline
\end{tabular}

Based on data from the Central Statistical Office (GUS) for 31 December 2017, there were 8096258 children and teenagers up to 20 years of age in total [12]. In 2017, there were 997 children and teenagers up to 20 years of age with T2DM in Poland. This shows that in 2017, the problem of T2DM concerned about $0.01 \%$ of all children and youth up to 20 years of age in Poland. The risk of occurrence of T2DM in the group $\leq 20$ is RR $=0.0086[95 \% \mathrm{Cl}(0.0081,0.0091)]$ in comparison to the group $>20$ years of age.

\section{Discussion}

The frequency of occurrence of T2DM in the population of people up to 20 years of age is relatively stable. Depending on the year of observation, children and adolescents comprised between $0.33 \%$ and $0.22 \%$ of all patients with T2DM. However, the highest percentage was noted in the first two years of observation, and it then decreased slightly and remained at a relatively stable level. The problem of T2DM concerned, on average, 255 children up to 10 years of age and adolescents between 11 and 20 years of age. On the scale of the entire population of children and adolescents in Poland, the problem of T2DM concerned about $0.01 \%$.

These results showed the incidence of T2DM in the paediatric population to have a range of 3.3/1 000. In American epidemiological studies, it was shown that the discussed phenomenon concerned 1-51/1 000, but this depended upon the ethnic group $[4,13]$. Our indicators of T2DM occurrence in children and young adults are lower than in the USA. The American study showed that the rate of T2DM in 10-14 year-olds was 8.1/100 000, and in 15-19 year-olds - 11.8/100 000. The lowest rates were observed in non-Hispanic white youth, but the highest was in $\mathrm{Na}$ tive Americans [14]. For type 2 diabetes, the U.K. incidence was $0.53 \cdot 100,000^{-1} \cdot$ year $^{-1}(0.41-0.68)$. What was also noted in this research was the context of ethnic origin. Children of ethnic minorities were probably greatly overrepresented by those of black and South-Asian origin [15]. The prevalence of T2DM in the paediatric population in Europe is approximately 2.5:100 000 [4].
In this context, our results are relatively in compliance with European data. T2DM accounted for $1.3 \%$ of all cases of diabetes. In Europe, the highest reported prevalence of childhood T2DM is in the UK [16].

Literature stresses the fact that the number of youth diagnosed with T2DM increased dramatically [4, 13-15]. Thus, actions should be undertaken that would be aimed not only at prevention of T2DM in children and adolescents but also at ensuring proper health and psychological care for them. The time period up to 20 years of age is related not only to sexual maturation, but also to creating lasting social bonds and shaping personality. The occurrence of a chronic illness (e.g. diabetes) at this time may disturb that psycho-social development [17]. Therefore, it seems crucial to elaborate upon an appropriate strategy of working with youth diagnosed with this type of diabetes so as to enable them access to more effective therapy [18]. Many people may rebel against this or apply some protective mechanisms that would help them deny the existence of this illness. This translates into the that behaviour such people present, e.g. they may undertake behaviour that would deny the existence of the illness. As a result, this will negatively influence the effectiveness of the therapy and intensify the symptoms. Intensification of symptoms reflects negatively on psycho-social development, thus creating a vicious circle [19]. It is worth stressing the fact that the majority of works on the psychological functioning of children and young adults with diabetes primarily concerns type I diabetes [6, 20-22]. However, the number of works on children with T2DM is limited $[6,23,24]$. A similar phenomenon will probably occur in children and young adults with T2DM; although, Nadeau et al. [6] point out that the issue of psychological problems in children and adolescents with diabetes may be slightly different. This is related to the fact that T2DM in children is different from T2DM in adults. For this reason, health education concerning children and adolescents requires a different approach. Nurses' and doctors' skills could play an important role in this context. T2DM has a negative impact on the lifestyle of the paediatric population, as well as psycho-social functions. These changes also influence adherence to medical recommendations. Because of this, nurses and doctors have to be well-prepared for clinical work with children and adolescents with T2DM [6].

Our research shows that the trend of occurrence of T2DM in children and adolescents is stable. The incidence of T2DM in children under 10 years of age is lower than in adolescents (11-20 years). Moreover, the increase in the frequency of occurrence of obesity among children and adolescents may contribute to the significant increase in the frequency of occurrence of diabetes of this type in this group $[4,25]$. What seems of particular importance is fostering a healthy and active lifestyle among children and adolescents. Annually, 255 children up to the age of 10 were diagnosed with T2DM and required lifestyle changes, including modification of their eating behaviour. Changing the eating behaviour of these children requires not only educating the child but also their parents. In this context, appropriate communicative skills and adequate preparation by physicians to work with children and adolescents seem of special significance, especially with reference to those who do not accept but rather deny their illness [26]. Having a proper rapport with a teenager may allow the physician to influence the psychological state of the patient positively. This may be of key importance in the context of research carried out by Lord et al. [27]. The above-mentioned researchers showed that a positive mood increases adherence to medical recommendations. This was associated with better glycaemic control, less psychological symptoms and better well-being. In addition, the effect of a positive mood was long term.

Adequate nutritional education is important for the prevention of T2DM among children and adolescents. In this context, nurses and doctors as educators of healthy eating can play an important role. The presented studies have shown that there 
is a relatively constant T2DM trend among children and adolescents. Still, it is reasonable to support doctors and nurses in acquiring the right skills. Appropriate skills will allow for effective nutritional education for children and adolescents. This is particularly important, because the specificity of this education is different to that of adults. It is important to give the nurse the right tools to work with children and adolescents.

\section{Limitations of the study}

The present study is not devoid of limitations. One of these is taking into account only patients benefiting from state medical centres and private medical centres that signed a contract with the NFZ, under which medical services are financed from public funds. In this study, patients who benefited from private medical centres that had not signed a contract with the NFZ were not included. For this reason, the selection of patients for the study may be another limitation. Another important limitation of the study is the inclusion of only those patients that actively participated in treatment and "benefitted" from medical visits. Our analyses do not take into account the so-called undiagnosed patients, i.e. those who are not aware of their illness or deny it.

Despite the above-mentioned limitations, our 8-year study, which encompasses a representative Poland-wide sample, provided new expertise on the topic of the prevalence of T2DM in children and young adults.

\section{Conclusions}

The trend of T2DM occurring in children and adolescents is relatively stable and is an important challenge for contemporary family medicine. This issue requires undertaking appropriate actions aimed at improving medical care addressed to these patients, as well as fostering preventive actions. Doctors and nurses play an important role in the health education of T2DM patients. For this reason, strengthening the skills of doctors and nurses in this area is crucial. Additionally, actions aimed at evaluating the psycho-social functioning of these children and adolescents with T2DM should be undertaken in the context of following medical recommendations.

Source of funding: This work was funded from the authors' own resources.

Conflicts of interest: The authors declare no conflicts of interest.

\section{References}

1. Zheng Y, Ley SH, Hu FB. Global aetiology and epidemiology of type 2 diabetes mellitus and its complications. Nat Rev Endocrinol 2018; 14(2): 88-98.

2. Kaiser AB, Zhang N, van der Pluijm W. Global prevalence of type 2 diabetes over the next ten years (2018-2028). Diabetes 2018; 67(Suppl. 1), doi: 10.2337/db18-202-LB.

3. Reinehr T. Type 2 diabetes mellitus in children and adolescents. World J Diabetes 2013; 4(6): 270-281.

4. Pulgaron ER, Delamater AM. Obesity and type 2 diabetes in children: epidemiology and treatment. Curr Diab Rep 2014; $14(8): 508$.

5. Alva ML, Hoerger TJ, Zhang P, et al. Identifying risk for type 2 diabetes in different age cohorts: does one size fit all? BMJ Open Diabetes Res Care 2017; 5(1): e000447.

6. Nadeau KJ, Anderson BJ, Berg EG, et al. Youth-onset type 2 diabetes consensus report: current status, challenges, and priorities. Diabetes Care 2016; 39(9): 1635-1642.

7. Concato J. Is it time for medicine-based evidence? JAMA 2012; 307(15): 1641-1643.

8. Regulation of the Minister of Health of 20 June 2008 on the scope of necessary information collected by public benefit provider, detailed manner of registering this information and their transfer to entities authorized to finance health benefits under public funding. Journal of Laws 2018; 128(801): 6636-6695.

9. WHO. International statistical classification of diseases and related health problems. Vol. 1. World Health Organization; 2004.

10. Wyszkowska Z. Koszty leczenia wybranych chorób cywilizacyjnych w opiniach respondentów. Nierówności społeczne a wzrost gospodarczy 2015; 43: 163-172 (in Polish).

11. Armitage P, Berry G, Matthews J.N.S. Statistical methods in medical research. Hoboken: John Wiley \& Sons; 2008.

12. GUS. Baza demograficzna. 2017 [cited 31.12.2017]. Available from URL: http://demografia.stat.gov.pl/bazademografia/Tables.aspx (in Polish).

13. Fagot-Campagna A, Pettitt DJ, Engelagu MM, et al. Type 2 diabetes among North adolescents: an epidemiologic health perspective. J Pediatr 2000; 136(5): 664-672.

14. SEARCH for Diabetes in Youth Study Group* TWGFT. Incidence of diabetes in youth in the United States. JAMA 2007; 297(24): 2716$-2724$.

15. Haines L, Chong Wan K, Lynn R, et al. Rising incidence of type 2 diabetes in children in the U.K. Diabetes Care 2007; 30(5): 1097-1101.

16. Zimmet P, Alberti KG, Shaw J. Global and societal implications of the diabetes epidemic. Nature 2001; 414(6865): 782-787.

17. Ashraff S, Siddiqui MA, Carline TE. The psychosocial impact of diabetes in adolescents: a review. Oman Med J 2013; 28(3): 159-162.

18. Wiebe DJ, Helgeson V, Berg CA. The social context of managing diabetes across the life span. Am Psychol 2016; 71(7): 526-538.

19. Esmaeilinasab M, Ebrahimi M, Mokarrar MH, et al. Type II diabetes and personality; a study to explore other psychosomatic aspects of diabetes. J Diabetes Metab Disord 2016; 15: 54.

20. Jaser SS, Patel N, Xu M, et al. Stress and coping predicts adjustment and glycemic control in adolescents with type 1 diabetes. Ann Behav Med 2017; 51(1): 30-38.

21. Hannonen R, Eklund K, Tolvanen A, et al. Psychological distress of children with early-onset type 1 diabetes and their mothers' wellbeing. Acta Paediatr 2015; 104(11): 1144-1149.

22. Boogerd EA, Damhuis AMA, Van Alfen-van der Velden JAAE, et al. Assessment of psychosocial problems in children with type 1 diabetes and their families: the added value of using standardised questionnaires in addition to clinical estimations of nurses and paediatricians. J Clin Nurs 2015; 24(15-16): 2143-2151.

23. Jaser SS. Psychological problems in adolescents with diabetes. Adolesc Med State Art Rev 2010; 21(1): $138-151$.

24. Brady CC, Vannest JJ, Dolan JM, et al. Obese adolescents with type 2 diabetes perform worse than controls on cognitive and behavioral assessments. Pediatr Diabetes 2017; 18(4): 297-303.

25. Mauvais-Jarvis F. Epidemiology of gender differences in diabetes and obesity. Adv Exp Med Biol 2017; 1043: 3-8.

26. Crossley J, Eiser C, Davies HA. Children and their parents assessing the doctor-patient interaction: a rating system for doctors' communication skills. Med Educ 2005; 39(8): 820-828.

27. Lord JH, Rumburg TM, Jaser SS. Staying positive: positive affect as a predictor of resilience in adolescents with type 1 diabetes. $J$ Pediatr Psychol 2015; 40(9): 968-977. 
Tables: 1

Figures: 1

References: 27

Received: 28.07.2020

Reviewed: 5.08.2020

Accepted: 8.09.2020

Address for correspondence:

Mariusz Panczyk, PhD

Zakład Edukacji i Badań w Naukach o Zdrowiu

Wydział Nauk o Zdrowiu

Warszawski Uniwersytet Medyczny

ul. Żwirki i Wigury 81

02-091 Warszawa

Polska

Tel.: +48 22 572-04-90

E-mail: mariusz.panczyk@wum.edu.pl 